\title{
UNA VISIÓN GLOBAL DEL SECTOR HORTÍCOLA
}

\author{
Jairo A. Osorio* \\ Adolfo Hernández**
}

* Ingeniero Agrónomo - Ph.D.

Investigador CORPOICA

** Economista-M.Sc.

Investigador CORPOICA

Grupo de Investigación en Modelación de Sistemas Agrícolas -MODESA-: Corpoica, Escuela de Ingeniería Industrial y Estadística de la Universidad del Valle, Cenicaña.

\section{RESUMEN}

Aunque las hortalizas forman parte de la base alimentaria, su consumo es muy inferior al recomendado. Si bien se dispone de recursos físicos para una producción eficiente se están importando hortalizas y ellas no han provocado procesos de desarrollo regional. Las hortalizas en Colombia son el resultado de intercambios culturales en las migraciones y en el intercambio comercial, para atender intereses, tradiciones y usos. El descubrimiento trajo hortalizas de Europa y se fueron hortalizas de América para Europa. Hoy, el sector tiene buenas perspectivas por su aporte a la alimentación humana y por el 
florecimiento de los negocios agroalimentarios. Las hortalizas en todas las regiones de Colombia generan grandes retos para la agricultura y la investigación. La producción de hortalizas tiene grandes limitantes tecnológicos por la importación de semilla, la alta incidencia de plagas y enfermedades, el uso indiscriminado de agroquímicos y las deficientes prácticas de manejo. También tiene limitantes estructurales por el deterioro de los recursos naturales, la deficiente infraestructura, los altos costos de producción y la falta de agregación de valor al producto. De esta manera, hoy existe un estancamiento del área sembrada y de los rendimientos de las principales hortalizas. Las hortalizas enfrentarán en el inmediato futuro el condicionamiento de la protección de la salud humana y de formas de desarrollo que contribuyan a mejorar los ambientes productivos rurales y a conservar los recursos naturales. El sector requerirá políticas coherentes para mejorar las formas de producir y mercadear, donde el propósito colectivo sea el motor principal y contribuya al desarrollo humano y a la eficiencia económica, sobre la base del desarrollo técnico y científico.

Palabras claves: Horticultura, desarrollo humano y regional, tecnología, medio ambiente.

\footnotetext{
ABSTRACT

Vegetables are a main part of the food pyramid but consumption is a lot less than the minimum recommended. Even though we have physical resources available for an efficient production, we are importing vegetables and horticulture has not provoked processes of regional development. Horticulture in Colombia is the result of cultural interchange coming from migration and trade intended for attending particular interests, traditions, and uses. The discovery brought vegetables from Europe to America and took vegetables on the opposite way. Today, horticulture has good perspectives given its
}

contribution to the human feeding and also given the emerging agriculture and food industry. Everywhere in Colombia, vegetables are a source of challenges for agriculture and research. Vegetables' production faces great technological constraints because of seed's importation, high illnesses and plagues' incidence, indiscriminate use of chemicals, and poor handling customs. There are also structural restrictions due to deterioration of natural resources and lack of value aggregation to the product. This way, sowed areas and productivity of the main vegetables have stopped growing. Horticulture will face in the near future restrictions due to the human health protection. It will also face challenges on the developing ways leading to improving the rural production environments and preserving natural resources. Horticulture will need coherent policies to improve the production and distribution means; in such a way that the joint goal be the main motor and that it contributes to human development and economic efficiency on the basis of technical and scientific development.

KEYWORDS: horticulture, human and regional development, technology, environment

\section{INTRODUCCIÓN}

"Nuestro problema no es falta de técnica o falta de plata para sembrar; porque ya ni tenemos recursos para comprar la comida": Un campesino de Bolívar, Valle del Cauca.

Este corto fragmento de la historia actual, es un claro llamado a preocuparnos por un sector de nuestra ruralidad, que a pesar de albergar la materia prima para construir un paisaje donde florezca el desarrollo humano, se encuentra sumido en una crisis social y económica profunda. Muchos eventos de la historia de la horticultura Colombiana son páginas que nunca se escribieron, otras permanecen inéditas o

1 Declaración de un agricultor horticultor del Morte del Valle 
ignoradas, otras fragmentadas con el paso de los años.

La geografía de Colombia nos ofrece una gran variedad de recursos para la producción. En todos los lugares del país se cultivan las hortalizas, componentes fundamentales de la dieta; sin embargo, es preocupante la dependencia creciente en la importación de bienes de origen hortícola al país. ¿Qué oportunidades tenemos y qué podríamos hacer para que la horticultura sea más dinámica en los procesos de crecimiento y desarrollo regionales?

En el presente escrito se busca ofrecer una perspectiva general del sector hortícola, a través de una mirada a la historia pasada, una toma de conciencia de la historia del presente y una visión de la posible historia futura, apoyadas en fragmentos de su historia, no con la pretensión de dar respuestas sino por el contrario, plantear algunos interrogantes, haciendo referencia al Sur-occidente Colombiano, región con todas las características de clima del país y por lo tanto donde se producen la mayoría de las hortalizas y donde confluyen también la diversidad de formas de producción.

\section{UNA MIRADA A LA HISTORIA DE LAS HORTALIZAS}

Entender las hortalizas como un sistema de producción significa considerar su evolución cultural, las transformaciones de saberes y de técnicas, la dinámica social y las formas de organización alrededor de la producción y las influencias de las costumbres productivas sobre el medio ambiente.

La historia de los alimentos está ligada a las migraciones de las especies vegetales, resultado de procesos de colonización e intercambio comercial que buscan atender diversas necesidades e intereses, y a las tradiciones culturales expresadas en el uso de productos autóctonos. Para el nuevo mundo, los eventos del descubrimiento y colonización por el imperio español, introdujeron nuevos modelos de producción y consumo de alimentos vegetales que fueron cambiando las relaciones de los pobladores nativos con su medio natural; así como sus costumbres y técnicas productivas. Esos eventos también originaron el movimiento de las hortalizas nativas y la entrada de especies exóticas al nuevo mundo. Los fenómenos de migración de especies hortícolas al viejo continente se dieron por el interés de los europeos en productos exóticos (nuevo colorido y nuevos sabores en la alimentación); situación contraria al rechazo del indígena a cultivar por obligación las especies introducidas como el trigo, la cebada y las hortalizas porque no se ajustaban al sistema de siembra indígena... "0.4 hectáreas de tierra sembradas de tubérculos, pueden alimentar a una familia de cinco personas, pero la misma superficie con cereales es insuficiente para alimentar dos personas, fuera de que se requiere mayor cantidad de trabajo", además se debía pagar tributo en especie y no se podían atender los cultivos ancestrales.

La introducción de hortalizas a América $^{3}$ provenientes de Europa, tal como se muestra en el cuadro anexo, se dio por el interés del conquistador de mantener su modelo de consumo. Así llegaron los garbanzos que los romanos cultivaban para los pobres, las arvejas que Mendel usó para formular los principios de la herencia; las habas cultivadas por los egipcios, las lentejas provenientes del Mediterráneo, los ajos, el perejil, el cilantro, las cebollas y el jengibre, entre otras. En el mismo período de la Conquista, los españoles probaron y apreciaron muchos alimentos y productos del indígena, de los cuales se introdujo a Europa el ají, el tomate,

\footnotetext{
2 Declaración de un agricultor horticultor del Morte del valle.

3 Cfr. ROJAS, L. 1993. Aportes alimenticios del viejo al nuevo mundo. Editorial Voluntad. 197 p.
} 
las calabazas, el zapallo, el fríjol y una serie de verduras que ellos llamaron verdolagas y que abundaban en la variadísima comida indígena.

A partir de estas introducciones, algunas hortalizas originarias del nuevo mundo empezaron a formar parte de la base de la agricultura y la alimentación mundial. El fríjol, especie indispensable en el equilibrio alimentario de los Aztecas y los Incas, con un alto contenido de proteína, se convirtió en un complemento del maíz que es un energético. Los pimientos ${ }^{5}$ (chiles, axies; especies domesticadas, unos 7000 años antes de nuestra era y unos 2000 años antes que el maíz) fueron especias que tuvieron una rápida adopción en todas las cocinas del mundo. El tomate, planta originaria de los Andes Americanos, es hoy en día la hortaliza más consumida. Los únicos cultivares silvestres de esta especie existen en América y son portadores de genes valiosos como aquellos que confieren resistencia a plagas y enfermedades y a partir de los cuales se puede pensar en combatir los principales problemas sanitarios de los cultivos actuales y aminorar los costos de su control.

Al sector hortícola así conformado, no se le ha reconocido nunca toda su importancia en nuestra sociedad; y sólo recientemente ha venido ganando la atención general, no sólo por su aporte a la nutrición sino también por los negocios que en torno a él se vienen dinamizando y por su papel en la generación de empleo y en la satisfacción de las necesidades de la dieta de los

\footnotetext{
${ }^{4}$ Cfr. BOYAT, A 1992. Haricot. En : Les plantes de la decouverte. Le Courrier de la Planette. Moviembre, 1992. Agropolis, Montpellier.

${ }^{5}$ Cfr. BARReAU, J. 1992. Piments. En Les Plantes de la decouverte. Le Courrier de la Planette. Moviembre, 1992, Agropolis, Montpellier.

6 Cfr. PHILOUZE, J. 1992. Tomate. En Les Plantes de la decouverte. Le Courrier de la Planette. Moviembre, 1992. Agropolis, Montpellier.
}

Colombianos. La celebración de la XVII reunión anual de la Sociedad Americana de Ciencias Hortícolas de las Regiones Tropicales (AS.H.S.) en la ciudad de Palmira, (Colombia), en Julio de $1969^{7}$ señaló la necesidad de lograr una vigorización de la horticultura y el inicio de trabajos de investigación sistemáticos. A partir de entonces hubo un esfuerzo oficial para estudiar las potencialidades y problemas de las hortalizas en varias regiones del país y se emprendió la tarea de fortalecer la investigación ya iniciada ${ }^{8}$ en el Altiplano de Cundinamarca y Boyacá, Ocaña, Antioquia, Mariño y el Valle del Cauca. Estos esfuerzos, que duraron 20 años se fueron debilitando al darse cambios institucionales que redujeron a un mínimo la investigación hortícola desde hace una década.

Después de siglos de desarrollos aún desconocidos de nuestra horticultura, podemos decir que "no existe región en Colombia donde no se cultive, aunque sea en mínima extensión, alguna hortaliza para consumo familiar o para el mercado..$^{\prime 9}$ La Horticultura Colombiana presenta al nuevo milenio una canasta llena de limitantes tecnológicos (semillas importadas, alta incidencia de plagas, uso indiscriminado de agroquímicos, deficientes prácticas de manejo de cultivos) y estructurales (deterioro de recursos naturales, infraestructura insuficiente, dependencia de productos importados, altos costos de producción y baja rentabilidad). Al mismo tiempo se evidencian oportunidades y potencialidades que deben captar la atención de nuestros dirigentes, de nuestra institucionalidad y de mujeres y hombres de la academia y la ciencia.

\footnotetext{
${ }^{7}$ Cfr. CAICEDO, L. 1982. Horticultura. Universidad Macional de Colombia. Palmira. 246 p.

8 Cfr. YEPES, E. 1957. La investigación agrícola en Colombia. En: Economía Colombiana. Vol. 12, Mo. 33. Ver también ICA, 25 años de investigación. Memorias de la Institución.

9 Cfr. JARAMILLO, J. y LOBO, M. 1986. Hortalizas. Manual de Asistencia Técnica. ICA.
} 


\begin{tabular}{|c|c|}
\hline \multicolumn{2}{|c|}{$\begin{array}{l}\text { PRIMCIPALES PLAMTAS COMESTIBLES IMTRODUCIDAS EM AMÉRICA } \\
\text { DESDE EL DESCUBRIMIEMTO Y EM LOS AÑOS SIGUIEMTES }\end{array}$} \\
\hline Mombre Común & Lugar de Origen \\
\hline $\begin{array}{l}\text { Acelga } \\
\text { Achicoria } \\
\text { Alcachofa } \\
\text { Apio } \\
\text { Arveja-guisantes } \\
\text { Berenjena } \\
\text { Berros } \\
\text { Brócoli } \\
\text { Caraotas (fríjol negro) } \\
\text { Cebolla de tallo } \\
\text { Cebolla de bulbo } \\
\text { Coles } \\
\text { Coliflor } \\
\text { Espárragos } \\
\text { Espinacas } \\
\text { Garbanzos } \\
\text { Haba blanca } \\
\text { Haba roja } \\
\text { Haba Bachalay } \\
\text { Habichuela - alubias } \\
\text { Lechugas } \\
\text { Lentejas } \\
\text { Mabo } \\
\text { Pepino cohombro } \\
\text { Puerros } \\
\text { Rábano } \\
\text { Remolacha } \\
\text { Repollo } \\
\text { Ruibarbo } \\
\text { Zanahorias }\end{array}$ & $\begin{array}{l}\text { Sur de Asia } \\
\text { Mediterráneo } \\
\text { Mediterráneo europeo y norte de África. } \\
\text { Diversos sitios. } \\
\text { India, Mediterráneo, África Oriental. } \\
\text { India tropical, China subtropical. } \\
\text { Mediterráneo } \\
\text { Turquía, Egipto } \\
\text { África } \\
\text { China } \\
\text { Persia, Afganistan, Palestina } \\
\text { Sur de Europa, Mediterráneo, Turquía, Egipto. } \\
\text { Turquía, Egipto. } \\
\text { Europa y Mediterráneo. } \\
\text { Armenia y Asia Menor. } \\
\text { Asia Menor. } \\
\text { Grecia y Roma. } \\
\text { Egipto. } \\
\text { Babilonia } \\
\text { India } \\
\text { Cáucaso, regiones mediterráneas. } \\
\text { Mediterráneo, Cercano Oriente. } \\
\text { Europa. } \\
\text { Asia, África tropical. } \\
\text { Asia } \\
\text { China, Egipto. } \\
\text { India, Persia, Egipto, Mediterráneo. } \\
\text { Mediterráneo } \\
\text { Asia y el Tibet. } \\
\text { Asia Menor, Japón. }\end{array}$ \\
\hline
\end{tabular}




\section{LA HISTORIA ACTUAL DE NUESTRA HORTICULTURA}

El consumo alimentario en Colombia varía sustancialmente de región en región, la mayoría de los productos provienen del campo y no de la industria de alimentos, esto es que la producción de alimentos está en procesos primarios de elaboración.10 En la dieta de los Colombianos, las principales hortalizas $^{11}$ son el tomate, la arveja, las cebollas y la zanahoria, las cuales ocupan el $80 \%$ del área hortícola cultivada. Las cifras sobre el comportamiento de la agricultura durante los últimos 10 años en Colombia, muestran que ha ocurrido una drástica reducción de la superficie dedicada a la producción de cultivos transitorios. Las hortalizas, así mismo muestran un estancamiento del área sembrada y los rendimientos. Tradicionalmente, la producción hortícola en Colombia se ha concentrado en el altiplano Cundiboyacense, el Valle del Cauca, la provincia de Ocaña, el oriente Antioqueño y la zona andina Mariñense. A nivel nacional, las hortalizas representan el $\mathbf{2 . 5 \%}$ de la superficie cultivada, el $2.9 \%$ del volúmen total de producción, el $6.2 \%$ del valor de la producción y participan con cerca del $10 \%$ del empleo generado en el sector. ${ }^{12}$

En el Sur-Occidente Colombiano, (Departamentos de Valle del Cauca, Cauca y Mariño), se cultivan aproximadamente 12.500 hectáreas con hortalizas que ocupan 2.500.000 jornales al año. ${ }^{13} \quad$ La mayor concentración de la

10 Cfr. MACHADO A. 1986, El problema alimentario en Colombia, CID, Universidad Macional de Colombia.

11 Cfr. Encuesta nacional de alimentación, nutrición y vivienda, 1981. Citado por MACHADO A., En Problema alimentario en Colombia, CID, Universidad nacional. Pág. 27.

12 Cfr. CORPOICA, 1998. Sector agrícola en Colombia: Indicadores para el ordenamiento de especies agrícolas. Publicación de la Secretaría de Agricultura y Fomento del Valle.

13 Cfr. URPA - Valle de Cauca, 1998. Evaluaciones Agrícolas. Publicación de la Secretaría de Agricultura y Fomento del Valle. producción ocurre en zonas de ladera, en predios de extensiones menores a dos hectáreas, donde además de los limitantes tecnológicos y el deterioro de los recursos naturales, son drásticos y crecientes los problemas de manejo de cosechas y mercadeo de productos.

Las zonas hortícolas en el Sur-Occidente del país presentan serios problemas sociales y tecnológicos, responsables del bajo nivel de vida y los altos riesgos de inversión que caracterizan este sector ${ }^{14}$ Aspectos que contribuyen al estado actual de crisis son la ausencia de factores para el desarrollo humano en el campo y la creciente migración a la ciudad; el crédito agrícola escaso y costoso; la total dependencia de insumos externos costosos; el poco conocimiento de alternativas eficientes de producción (uso excesivo y generalizado de fertilizantes $y$ agroquímicos ); el deterioro del medio ambiente y de la salud humana; y los bajos niveles de organización y articulación de los distintos eslabones de la cadena productiva.

Las tendencias en la composición de la estructura de costos para el sector hortícola en el período 1989 a 1998 indican: 1) incrementos entre $300 \%$ y $700 \%$ en los costos de producción; 2) caída de 10 a 16 puntos porcentuales en la generación de empleo, especialmente en la ladera; 3) los insumos han mantenido sus niveles de participación del costo total en la zona plana, pero se han elevado en la ladera, de $37 \%$ en 1989 al 45-49\% en los últimos tres años; 4) incremento de la participación de los agroquímicos en los costos totales, tanto en la zona plana (del 17 al 28\%) como en la ladera (del 26 al 37\%).

Los factores tecnológicos de la producción de

14 Cfr. CORPPOICA. 1996. Documento de Programación 1996. Momentos Uno y Dos. Octubre de 1996.

15 Cfr. URPA - Valle del Cauca, 1996. Evaluaciones Agrícolas. Publicación de la Secretaría de Agricultura y Fomento del Valle. 
hortalizas presentan características muy similares en las distintas zonas de la región y del país: baja sostenibilidad y competitividad relacionadas principalmente con una compleja problemática sanitaria y de deterioro de recursos productivos. Los suelos, tanto de las zonas planas como de la ladera, exhiben serios problemas de degradación (erosión, eutroficación, salinización, compactación), ocasionados por el laboreo excesivo, ausencia de coberturas, malas prácticas de irrigación y drenaje y uso excesivo de fertilizantes.

En Colombia, cerca del $90 \%$ de la semilla requerida para la producción de hortalizas (variedades e híbridos) se importa de diferentes países y exhibe problemas de calidad fisiológica y sanitaria. Este hecho representa un riesgo grande para la inversión y especialmente para la sanidad de los cultivos, ante la posibilidad de introducción de patógenos y plagas exóticas. De otro lado, los rangos de adaptación de las variedades importadas no se establecen técnicamente y tampoco se aplican criterios apropiados para la selección de zonas y métodos de producción de tales cultivares.

Los insectos plaga y las enfermedades fungosas, bacteriales, virales, causan pérdidas elevadas (40-100\% en casos como el pasador del fruto y la gota del tomate, los Thrips y los patógenos del suelo en la cebolla, la royas en la habichuela, etc. $)^{16}$ Gran parte de esta problemática se origina en la escasa adaptación de los cultivares importados a nuestros ambientes tropicales. Para el control de los problemas fitosanitarios, los productores hacen uso intensivo e indiscriminado de pesticidas, muchos de ellos de categorías toxicológicas altas ( $\mid$ y ||$)$, con aplicaciones calendario de elevada frecuencia durante todo el ciclo de los cultivos. El uso de mezclas de varios agroquímicos, una o dos veces por semana, es una práctica común que conlleva

16 Cfr. CORPOICA, 1998. Frutos de la investigación 1994 - 1997. Regional 5. Palmira, mayo de 1998 altos niveles de intoxicación de operarios agrícolas y familias campesinas, contaminación de suelos, aguas y alimentos hortícolas.

Las tecnologías de control biológico, de relativa efectividad, han demostrado niveles muy bajos de adopción por los productores, debido entre otras a las siguientes causas: a) corto tiempo de permanencia de los agentes introducidos en los ambientes naturales; b) escaso desarrollo real de componentes complementarios al control biológico, c) difícil acceso a los insumos biológicos por parte de los pequeños productores; d) baja calidad de los insumos biológicos. Todo esto demuestra claramente una debilidad en la concepción y aplicación del modelo de generación y transferencia de tecnología para realizar un manejo integrado de plagas y patógenos.

La comercialización de hortalizas en los Departamentos del Sur-Occidente del país, en los últimos 10 años ha experimentado un aumento de las importaciones de otros Departamentos productores y de países vecinos. Esta situación contrasta con la de los años 1975-1979, cuando parte de la producción de hortalizas se exportó a otros países. En 1977 por ejemplo, la exportación de hortalizas desde el Valle del Cauca generó divisas por 4.9 millones de dólares. Internamente, los mercados están segmentados por la preponderancia de intermediarios, lo que contribuye al desorden de la comercialización, como resultado de la ausencia de productores organizados.

La mayor variación del precio de las hortalizas para el consumidor final está determinada por el comportamiento de los precios de los mayoristas, quienes más se benefician de los grandes márgenes de intermediación existentes (15 a $70 \%)_{1}^{17}{ }^{18}$ Actualmente perduran problemas

\footnotetext{
17 Cfr. CCl, 1999. Margen de comercialización de las Hortalizas en Colombia. En: Exótica, Boletín CCI, Vol 10 Mo. 2, abril-junio de 1999

18 Cfr. IBIDEM.
} 
críticos de falta de confianza entre los actores y ausencia de mecanismos reguladores; además, la calidad aún no se valora en el mercado, en parte porque la demanda aún no es muy exigente; situación ésta que tiende a cambiar en la medida en que se modernizan los esquemas de comercialización.

El consumo interno de hortalizas ha venido aumentando en los últimos años, especialmente en los estratos medios de la población. Sin embargo, estudios recientes muestran que el consumo promedio por persona año de hortalizas en el país es muy estable y alcanzaría un máximo de 35.5 kilogramos por persona año; nivel muy bajo frente al consumo recomendado de cerca de 110 kg por persona. Aún con este bajo consumo, la producción nacional de hortalizas es insuficiente para satisfacer la demanda. El porcentaje del gasto en alimentación dedicado a las hortalizas en Colombia se mantiene entre $8 \%$ y $7 \%$, manteniéndose las mismas hortalizas de importancia en el consumo, aunque en 1994/95 la estructura del ingreso ha marcado un incremento en la importancia de nuevas hortalizas frescas en el gasto como la habichuela, la lechuga o el repollo. ${ }^{19}$

Las oportunidades que brindan las hortalizas en las condiciones actuales, pueden aprovecharse reconociendo y valorando su condición de componentes indispensables en la alimentación humana. Inducir y satisfacer un consumo mayor de hortalizas permitiría con un plan ordenado, aumentar las inversiones y la producción en regiones seleccionadas, e integrar gradualmente actividades complementarias de producción y comercialización.

$19 \mathrm{Cfr}$. CCl, 1999. La Estructura de gastos de los consumidores en Colombia. En: SIPSA Boletín Mensual Mo. 29. Agosto de 1999; y ESPAÑA, R. 2000. Hábitos estilo año 2000. En: Revista COCELCO, Mo. 6. Marzo de 2000 .

\section{EL SECTOR HORTICOLA: "UNA MIRADA A LA HISTORIA FUTURA"}

El sector hortícola es un complejo renglón de la economía, cuya dinámica, comportamiento y desarrollo se verán influenciados y movilizados por dos grandes fuerzas motrices de nuestra sociedad, como se muestra en la gráfica anexa:

1) La búsqueda de condiciones que beneficien la salud humana y 2) La búsqueda de formas de desarrollo que contribuyan a mejorar los ambientes productivos rurales y a conservar los recursos naturales. Estas tendencias universales de nuestra sociedad, son vectores de alta jerarquía que orientarán el desarrollo del sector hortícola, influenciando los procesos de producción, comercialización y consumo alimentario.

En nuestra sociedad del futuro se dará una creciente preocupación por la salud humana, fenómeno dinamizado por el auge de las Tecnologías de Comunicación e Información y los avances en el conocimiento de las ciencias médicas, entre otros. Esta creciente necesidad de garantizar salud va a generar cambios en los estilos de vida como la reducción del consumo de tabaco y alcohol, el incremento de la práctica del deporte y de actividades al aire libre, cambios en hábitos de alimentación, ajustes en los ambientes laborales y familiares, entre otros. Los avances en las ciencias de la salud influyen cada vez más para que se adopten modificaciones en las dietas como una manera de contribuir a un mejoramiento de la salud por la vía preventiva. Parte de tales modificaciones involucran la reducción del consumo de grasas y harinas, el aumento del consumo de frutas y hortalizas, selectividad en el consumo de proteína de origen animal y preferencias por productos alimenticios "inocuos".

Este tipo de cambios impone nuevos retos al mercado de las hortalizas. En primer término, se requiere que los procesos de comercialización 
canalicen una oferta mayor y más diversificada de productos hortícolas. En segundo lugar, se incorporarán con mayor fuerza altos estándares de calidad. Esta exigencia se trasladará directa e indirectamente al proceso de producción, el cual deberá: 1) adoptar metodologías eficientes para satisfacer la demanda en volúmenes crecientes, y 2) introducir cambios tecnológicos que reduzcan el uso de agroquímicos en el cultivo de hortalizas. En últimas, se deberán generar cambios en la industria alimentaria tradicional, para asumir por ejemplo, demandas crecientes de productos con calidad y presentación adecuada y de fácil uso como los precortados y desenvainados.

El progresivo deterioro de los recursos naturales disponibles para la producción agropecuaria, se refleja claramente en: 1) el agotamiento del potencial productivo y descomposición de los pequeños productores, la cuenca y el agro ecosistema; 2) la creciente dependencia de insumos externos y sintéticos, para mantener la producción; 3) contaminación de las distintas fuentes de agua; 4) pérdida acelerada de biodiversidad; 5) abandono de tierras y migración.

Esta grave problemática ha generado como respuesta una tendencia en la nueva horticultura a buscar alternativas para mejorar los ambientes productivos rurales, y a recuperar y conservar los recursos naturales, riqueza mayor de nuestras comunidades campesinas tropicales. Esta gran tendencia, paradigma actual de toda sociedad, nos indica la necesidad de adoptar cambios en las costumbres productivas y estilo de vida rurales.

De un lado, se impone con urgencia la exigencia por valorar, conservar y utilizar más racionalmente el escaso recurso hídrico, de enorme valor estratégico. De otro lado, se hará evidente la necesidad de implementar estrategias integrales y masivas de conservación de los suelos, y de introducir prácticas de cultivo poco lesivas a la fauna, flora y microflora del suelo.
En esta visión "futura" del sector hortícola y la movilización de sus procesos hacia la función que la sociedad le demanda, se destaca: 1) una importante fuerza motriz que ejerce - a través de los cambios en el consumo alimentario nuevas exigencias en los mercados; 2) el proceso de comercialización, de otra parte, capta los cambios que ocurren en el consumo, provoca a su vez otros cambios en él y demanda los ajustes correspondientes en los procesos productivos. Al mismo tiempo, este proceso canalizará progresivamente la reacción de la unidad productiva primaria (finca), en la forma de productos aceptables en el mercado, resultado de la adopción de prácticas agrícolas más amigables al ambiente, estrategias de producción limpia (uso racional de agroquímicos), y la selección de mejores productos a comercializar.

Una serie de ajustes de gran magnitud se deben dar en el sector hortícola para responder eficientemente a las demandas que la sociedad va imponiendo. Muchos de tales ajustes deben ocurrir en la institucionalidad pública y privada, conectada hoy muy débilmente con los tres procesos (producción, comercialización y consumo) esenciales de la cadena productiva hortícola. El propósito colectivo debe ser el motor principal de motivación para el aporte del individuo al cumplimiento de la misión del sector. En su dinámica, el nuevo sector hortícola debe contribuir al desarrollo humano a través del logro de objetivos como el desarrollo tecnológico y la eficiencia económica; a fin de garantizar el progreso, el desarrollo sostenible y la permanencia en el tiempo de una actividad productiva.

El sector hortícola requerirá de políticas coherentes para hacer ajustes importantes en la forma de producir y mercadear, y para promover grandes transformaciones en lo organizacional. La institucionalidad deberá jugar un papel muy influyente en esas transformaciones. Los ajustes y cambios tecnológicos que requiere la finca hortícola para satisfacer las nuevas tendencias 
del consumo y la necesidad de conservar el medio ambiente, se trasladarán como exigencia cada vez más específica a los sistemas de investigación y desarrollo tecnológico, el educativo y a los servicios de apoyo y regulación, entre otros.

La sociedad en su conjunto, deberá apropiarse de las potencialidades del sector hortícola porque éste representa una opción válida, como pocas, para sacar adelante a las comunidades rurales y de consumidores, de las crisis que hoy enfrentan, y enrutarlas en el camino del desarrollo que dictan los dos grandes paradigmas (fuerzas motrices). Para ello, se deben implementar formas de organización de productores, instituciones y demás agentes de las cadenas productivas, articuladas a programas integrales de desarrollo de las regiones.

Los nuevos esquemas de desarrollo y los Planes de Ordenamiento Territorial deberán considerar la horticultura en su dimensión económica, social y ecológica. Será un reto para los dirigentes y para las instituciones, conquistar el desarrollo del sector hortícola en un mundo tropical diverso, que requiere fortalecer su capital humano y necesita recursos y herramientas eficientes de ciencia y tecnología para su progreso. Las actuales orientaciones gubernamentales sobre análisis de cadenas productivas y acuerdos de competitividad, deberían ser un punto de arranque, de negociación y de compromisos para el desarrollo futuro del sector.

La horticultura deberá regresar a rutas más sostenibles en los próximos 20 años, adoptando esquemas de desarrollo compatibles con la misión de largo plazo (las fuerzas motrices y sus exigencias a la unidad productiva primaria). Algunos de los cambios que debemos generar deben valorar en la práctica la riqueza del mundo vegetal de nuestro trópico, contribuyendo así a la diversificación de la canasta hortícola y a la recuperación de aquellos genes valiosos para la futura producción limpia de nuestros alimentos.
La megadiversidad de nuestra microflora nativa será sin duda crucial para los futuros desarrollos de insumos y productos inocuos a utilizar en las prácticas de control sanitario. Así mismo, se deben generalizar las prácticas de uso eficiente y racional de los recursos agua y suelo, abandonando paulatinamente las prácticas que causan contaminación, deterioro y erosión y reemplazarlas por estrategias de recuperación del paisaje. Estos cambios y sus frutos son sin duda, un derecho inalienable y una aspiración de los consumidores lo mismo que de la familia campesina.

\section{CONCLUSIONES}

Las grandes tendencias mundiales así como las condiciones críticas de nuestra horticultura sugieren la necesidad de reflexionar sobre los retos de su desarrollo que tienen que ver con:

- Organización sectorial donde las decisiones políticas, las actividades institucionales, los diferentes actores de las cadenas productivas, y la generación de ciencia y tecnología estén interrelacionadas.

- Congruencia entre los programas de Seguridad Alimentaria y Planes de Ordenamiento Territorial con la necesidad de hacer un uso adecuado y sostenible de los recursos naturales disponibles.

- Promover el Desarrollo agroindustrial del sector hortícola para fortalecer la base alimentaria de la sociedad y crear tejido económico y social.

- Producción más limpia y menos dependiente de insumos externos para beneficio de la población en general y del ambiente.

- Fortalecer el desarrollo científico y tecnológico. El desarrollo y aplicación de métodos de manejo integrado de insectos plaga y patógenos, como alternativas al control químico es sin duda una de las necesidades más apremiantes de nuestros agricultores y consumidores.

- Políticas de comercio exterior compatibles 
con el desarrollo de la producción, consumo interno y una política de autoabastecimiento.

- Reducir las distorsiones e inequidades de la cadena hortícola que desfavorecen a los productores rurales.

- Pensar la educación como elemento central en el desarrollo futuro del sector.

La producción de hortalizas tiene una gran perspectiva de organización para responder a los retos del desarrollo y tiene como base una oferta ambiental diversa, suelos de alta calidad y vocación agrícola, y presencia de recursos hídricos superficiales y subterráneos valiosos. En el caso del suroccidente colombiano, la infraestructura de Vías y de Riego, el parque de maquinaria agrícola y una notable especialización de las micro-regiones, cercanía a mercados y puertos, la presencia de centros tecnológicos, así como las posibilidades de diversificación de la tecnología y de la producción, son ventajas que se pueden aprovechar. Sin embargo, sufre también serios problemas de contaminación y deterioro progresivo de las cuencas y del recurso suelo; a lo que se suman otras debilidades como el déficit de tecnologías apropiadas para el manejo de plagas y enfermedades, proliferación de intermediarios, falta de información de mercados, y en la ladera, el déficit de infraestructura y limitado uso de tecnologías ajustadas para optimizar el uso del agua.

Para iniciar la reactivación del sector, es necesario, por tanto, ejecutar proyectos de desarrollo socioeconómico, generación y transferencia de tecnología agrícola, inversión en el recurso humano y proyectos productivos de base campesina integrados hacia adelante..$^{20}$
20 Cfr. SECRETARÍA DE AGRICULTURA Y FOMEMTO DEL VALLE. 1996. Plan de Desarrollo Agropecuario del Valle del Cauca. Santiago de Cali, febrero de 1996. 


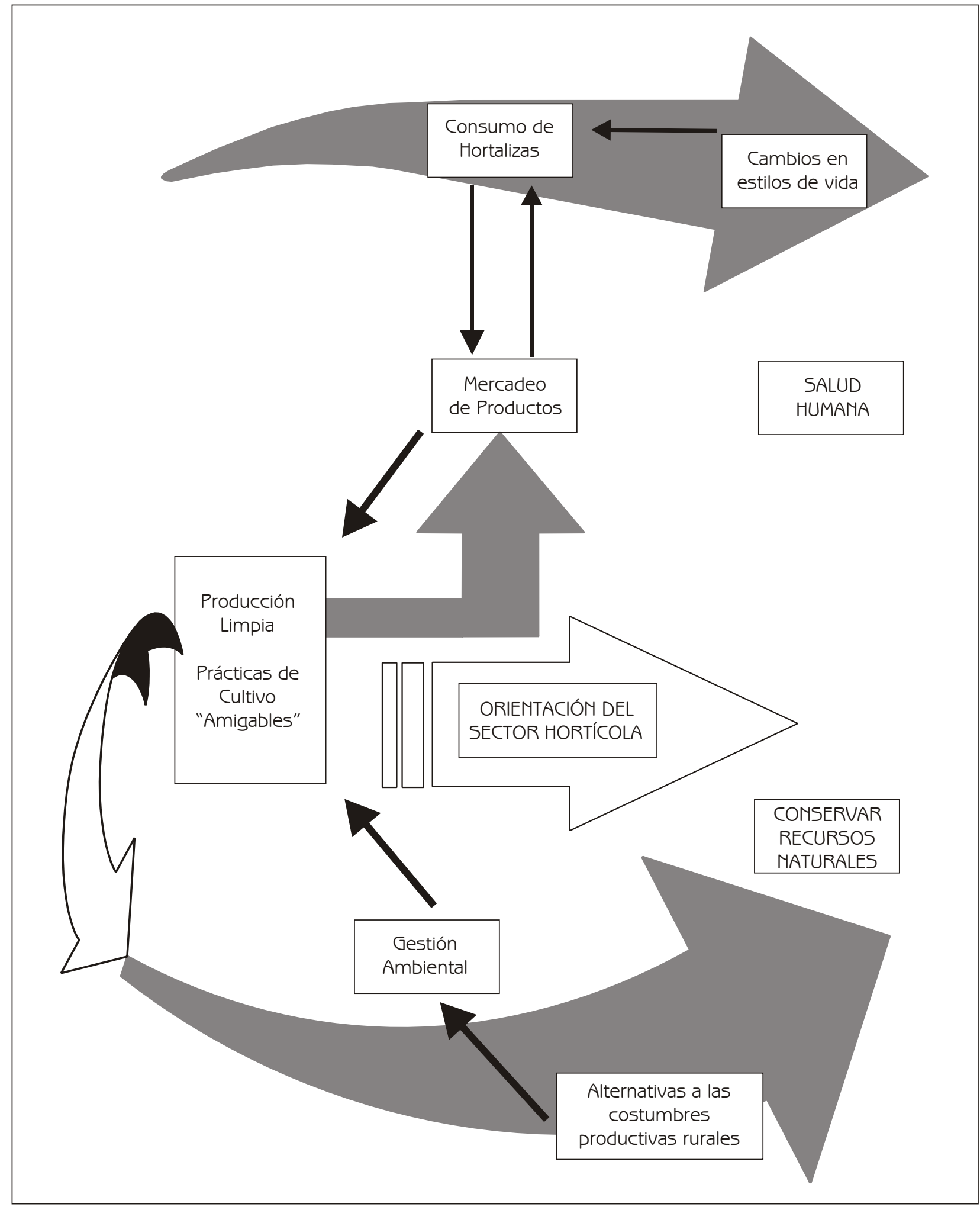

FIGURA 1. Fuerzas motrices de la sociedad contemporánea y la reacción del sector hortícola 